\title{
La superación de la metafísica de la subjetividad a través de una analítica de la coexistencia
}

\author{
Gustavo Salerno
}

CONICET/UNMDP

Resumen: En el presente trabajo caracterizo operativamente el pensar temprano de Heidegger como una "filosofia de la intersubjetividad". Esto me permite habilitar un contraste de su aporte frente a lo que define como "metafísica de la subjetividad": se trata de un horizonte filosófico que Heidegger critica, y que en este trabajo reconstruyo prestando especial atención a la fenomenología de Husserl. Este cotejo puede llevarse a cabo circunscribiendo el programa ontológico-hermenéutico de Ser y tiempo a los términos del estudio preparatorio que antecede a la pregunta por el ser, y de comprenderlo como una analitica de la coexistencia.

Palabras clave: subjetividad; analítica; coexistencia; fenomenologia; metafísica

\begin{abstract}
Overcoming the metaphysics of subjectivity through an analytic of coexistence". In this article, I operationally characterize Heidegger's early thinking as a "philosophy of intersubjectivity". This will allow me to make a contrast of his contribution to what he defines as "metaphysics of subjectivity": it is a philosophical horizon that Heidegger criticizes, and that I will reconstruct paying special attention to the phenomenology of Husserl. It is possible to make this comparison by circumscribing the ontological program of Being and Time to the terms of the preparatory study preceding the question of being, and of the understanding of it as an analytic of coexistence.
\end{abstract}

Keywords: subjectivity; analytics; coexistence; phenomenology; metaphysics 
Heidegger es un filósofo de la "intersubjetividad", aunque cierta él mismo no usara este término para definir su filosofia temprana por motivos que oportunamente explicaré. Si la denominación sirve para identificar a quienes en la contemporaneidad, yendo contra la tradición solipsista y monológica de la filosofia moderna, subrayaron la condición relacional e interdependiente de los "sujetos", entonces no hay dudas de que Ser y tiempo (1967) ${ }^{1}$ pertenece a este reposicionamiento.

En búsqueda de que esto resulte manifiesto y suficientemente argumentado voy a estructurar mi exposición del siguiente modo: en principio, caracterizaré la crítica que Heidegger realiza a la filosofia moderna al definirla como "metafísica de la subjetividad". Le otorgaré especial atención a la que -según los términos de dicha crítica- es una de sus expresiones paradigmáticas, a saber: la fenomenología de Husserl. Me parece oportuno y necesario recuperar esta particular lectura debido a que Heidegger concreta el camino que conduce a Sery tiempo como una transformación hermenéutica de la fenomenología (1). A partir de esto, me encontraré en condiciones de presentar con algún detalle las dos cuestiones más relevantes que implica el tema de este trabajo: los motivos por los cuales, según Heidegger, la investigación del ser (horizonte programático de la obra) requiere de un estudio previo y preparatorio acerca del ente que pregunta por el ser (horizonte analítico) (2) y los aspectos centrales de la "filosofia de la intersubjetividad" que resulta a partir de lo anterior. Consecuentemente, resultará justificado definir tal filosofia como una "analítica de la coexistencia" (3).

\section{Husserl como sintoma de la "metafisica de la subjetividad"}

La siguiente definición puede considerarse como parámetro de toda evaluación crítico-histórica de raigambre heideggeriana: "[1]a metafisica fundamenta una era, desde el momento en que, por medio de una determinada interpretación de lo ente y una determinada concepción de la verdad, le procura a esta el fundamento de la forma de su esencia” ${ }^{2}$. Esto quiere decir que una era

\footnotetext{
1 En el presente texto utilizo como referencia la edición preparada por Max Niemeyer Verlag (Tubinga, 2002 [1967]). Las citas y la paginación corresponden a esta versión del original.

2 Heidegger, M., "La época de la imagen del mundo", en: Caminos de bosque, Madrid: Alianza Editorial, 2012, p. 63.
} 
La superación de la metafisica de la subjetividad a través de una analitica de la coexistencia

o un tiempo histórico tienen su fundamento esencial de acuerdo al modo en que interpretan y conciben tanto el ser como la verdad. Tal interpretación (Auslegung) y tal concepción (Auffassung) son provistas por la metafísica. Por consiguiente, cuando decimos "metafísica de la subjetividad" estamos indicando que es la subjetividad quien ofrece la comprensión hegemónica del ser y la verdad propia de una época. Para Heidegger es lo que ocurre en la modernidad: la filosofia "entroniza" al sujeto. Entronizar es darle a algo una regencia, soberanía o dignidad superior, jerarquizarlo como primero y distinguirlo así del resto de lo que hay.

Ahora bien, en su escrito (cuasi) autobiográfico "Mi camino en la fenomenología" (1963), Heidegger presenta la filosofia husserliana dentro del campo conceptual e histórico que acabo de describir. Naturalmente, la lectura heideggeriana puede $-\mathrm{y}$, a mi juicio, debe- ser objeto de una exhaustiva revisión, pues no solo son abundantes los testimonios y las investigaciones de especialistas acerca de los estudios sobre la intersubjetividad realizados por Husserl, sino que también se disponen de fuentes primarias y directas del propio autor sobre este tema ${ }^{3}$. Lo que aquí plantearé está restringido, entonces, a la recepción de la fenomenología hecha por Heidegger, respecto de la cual afirma: : "[1] a 'fenomenología pura' [de Husserl] es la 'ciencia fundamental' de la filosofia, acuñada por aquella. 'Pura' quiere decir 'fenomenología trascendental'. Pero con 'trascendental' se alude a la 'subjetividad' del sujeto cognoscente, agente y valorativo. Ambos términos, 'subjetividad' y 'trascendental', indican que la 'fenomenología' se sumía consciente y decididamente en la tradición de la filosofia moderna..."

La filiación de la fenomenología husserliana a la filosofia moderna significa, pues, su interpretación como expresión sintomática de una tradición que ha comenzado con el ego cartesiano. Una definición de "metafísica de la subjetividad" concordante con lo que venimos planteando es la siguiente:

\footnotetext{
3 Señeros son los estudios de Julia Valentina Iribarne recogidos en La intersubjetividad en Husserl. Bosquejo de una teoría, Buenos Aires: Lohlé, 1987 o Edmund Husserl. La fenomenología como monadología, Buenos Aires: Academia Nacional de Ciencias, 2002. Imprescindible consultar respecto de la intersubjetividad fenomenológica Husserl, E., Zur Phänomenologie der Intersubjektivität. Texte aus dem Nachlass. Erster Teil. 1905-1920 (Hua. XIII), Zweiter Teil. 1921-28 (Hua. XIV), Dritter Teil 1929-35 (Hua. XV), Kern, I. (ed.), La Haya, Martinus Nijhoff, 1973 ; Aufsätze und Vorträge. 1911-1921. Mit ergänzenden Texten. Hua. XXV, Nenon, T. y H. Sepp (eds.), La Haya :Martinus Nijhoff, 1986; Aufsätze und Vorträge. 1922-1937. Hua. XXVII, Nenon, T. y H. Sepp (eds.), La Haya: Kluwer Academic Publishers, 1988.

4 Heidegger, M., "Mi camino en la fenomenología", en: Id., Tiempo y ser, Madrid: Tecnos, 2011, p. 97.
} 
se trata de la posición para la cual "la esencia de la verdad y la interpretación del ser estarian determinadas por el hombre como sujeto en sentido propio" 5 . Es preciso notar que no existe esta entronización del "sujeto" sin la correspondiente puesta en servidumbre del "objeto". La relación sujeto-objeto no es simétrica: el primero determina (incluso: instituye o constituye) al segundo. Esa asimetría es consustancial a la metafisica moderna. Esta desproporción instituye una época. En esta era, el sujeto domina, regula y hace inteligible al objeto. Este señorío se corresponde con la conversión de la filosofía en un discurso teorizante acerca de la realidad.

Si cotejamos la definición de la "metafísica de la subjetividad" ofrecida anteriormente con el propósito de Husserl de "regresar a las cosas mismas", entonces podemos notar -piensa Heidegger- que la fenomenología se ha extraviado en su camino. En efecto, el programa filosófico que se autocomprendía como conquista y aseguramiento de "las cosas mismas" (zu den Sachen Selbst) mediante la exención de todo prejuicio y, por ende, como auténtico positivismo ${ }^{7}$, culminaba concretándose como un análisis temático de la conciencia y del sujeto como fundamento absoluto inconmovible de verdad. El "objeto" tras la reducción fenomenológica" era siempre un objeto intencional, es decir, un objeto para la conciencia: Husserl insistía en que era un contrasentido distinguir entre el objeto intencional y real. Sin embargo -es esto lo que subraya Heidegger- la investigación fenomenológica provocaba mediante la epojé la des-mundanización (Entweltlichung) del objeto en la medida en que este era reducido a "lo pensado en tanto que pensado" (cogitatum qua cogitatum).

Sobre la base de lo hasta aquí dicho, voy a destacar dos cuestiones que considero significativas a la vista de los objetivos que persigue este trabajo. Primera cuestión: para Heidegger no hay dudas respecto de que, si se sigue a Husserl, las "cosas mismas" son tales en su ser y su verdad en tanto que una conciencia intencional las constituye. El en tanto que indica la concreción del punto arquimédico que aquel alcanza retomando a Descartes. En este sentido, permanece dentro del edificio filosófico moderno que Heidegger denomina "metafísica de la subjetividad": "[1]a cuestión primordial para Husserl no es en absoluto la cuestión acerca del carácter de ser de la conciencia; lo que a él le

\footnotetext{
5 Heidegger, M., Nietzsche, v. II, Barcelona: Destino, 2000, p. 158 y véase también pp. 25-29 y pp. 159ss.

${ }_{6}$ Waldenfels, B., "Fenomenología de la experiencia en Edmund Husserl", en: Areté, v. XXIX, 2 (2017), pp. 409-426.

7 Husserl, E., Ideas relativas a una fenomenología pura y una filosofia fenomenológica, México: FCE, 1962, p. 52.
} 
guía es, más bien: ¿cómo puede hacerse la conciencia objeto posible de una ciencia absoluta? Lo primordial, lo que a él le guía, es la idea de una ciencia absoluta. Esta idea: la conciencia ha de ser la región de una ciencia absoluta, no es que sea algo simplemente inventado, sino que es la idea que ocupa a la filosofia moderna desde Descartes"

De acuerdo a esto, lo efectivamente desarrollado por Husserl es (i) una caracterización del modo en que debe realizarse la fundamentación del conocimiento -a saber, alcanzando "apodicticidad"-y (ii) la localización del fundamento mismo en la conciencia. Sin embargo, incluso como gnoseología orientada trascendentalmente, la fenomenología deja sin tematizar el "carácter" o modo de ser de la conciencia intencional. Esto es: sabemos por la fenomenología husserliana cuál es la estructura de la conciencia (a saber: intencional), pero nada nos dice ella acerca de cómo existe la conciencia en concreto, en su cotidianidad, inmediata y regularmente. Como "pura", la conciencia tematizada calla la situación y las condiciones reales en que se encuentra.

Segunda cuestión: la existencia concreta y el correspondiente modo de ser de la conciencia quedan encubiertos también por motivos "metodológicos", pues el momento de la epojé -la reducción fenomenológica- pone en suspensión o inhibe ${ }^{9}$ precisamente aquello por lo que hay que preguntar: ¿qué y cómo vivencia el hombre concreto individual en esta y aquella situación fáctica? Vemos así que en Heidegger el interés recae justamente sobre aquello que la fenomenología invitaba a des-atender, a saber: la posición y la experiencia de quien se encuentra en la llamada "actitud natural": nuestro aquí y ahora (habitual, cotidiano) en relación con otros, con el mundo y con nosotros mismos. Esta situación del hombre en el mundo será en el análisis heideggeriano por principio irrebasable e ininterrumpible, contrario al proceder metódico husserliano según el cual "hay primero que perder el mundo por epojé, para recuperarlo en la meditación universal sobre sí mismo"10. Consecuentemente, Heidegger encuentra la "modificación" de la "actitud natural" hacia una "actitud refleja" (o reflexiva) pregonada por la fenomenología como mera artificiosidad. Para Husserl la reflexión implica la vía de acceso eminente para alcanzar la buscada apodicticidad y necesariedad científica; conecta, pues, con el ideal de la rigurosidad y

\footnotetext{
8 Heidegger, M., Prolegómenos para una historia del concepto de tiempo, Madrid: Alianza Editorial, 2006, pp. 139-140.

9 Husserl, E., Ideas relativas a una fenomenología pura y una filosofía fenomenológica, pp. 71-73.

${ }^{10}$ Husserl, E., Meditaciones cartesianas, México: FCE, 1994, §64, p. 231. Cf., Rodríguez, R., La transformación hermenéutica de la fenomenología. Una interpretación de la obra temprana de Heidegger, Madrid: Tecnos, 1997, p. 212.
} 
objetividad epistémica-cuestión reforzada por la pretendida postura "neutral" del fenomenólogo, que solo "describe" su objeto-. Para ello es necesaria la interrupción propiciada por la epojé. Ahora bien, este des-interés representa una "des-vivificación" de la vivencia (correspondiente a la "des-mundanización" del objeto que referi antes), costo necesario que habria que pagar si se asume que el propósito de la filosofia es lo auténticamente apodíctico, lo válido objetivamente. Sin embargo, frente a esto, "si cambiamos la óptica de la objetividad por la de la originalidad en su modo de darse, la vida fáctica quizá no pueda ser plenamente objetivable, pero es lo absolutamente originario, más atrás de lo cual no cabe ir" ${ }^{11}$.

En la tradición conformada por la "metafísica de la subjetividad", lo universalmente válido depende forzosamente de las condiciones de posibilidad que se adscriben a la actividad legislativa del sujeto cognoscente. Esto no podrá ser de otra forma mientras el esquema sujeto-objeto predetermine por completo el campo de investigación filosófica, en el sentido de colocar el ser y la verdad de cualquier objeto como dependiente del sujeto para el cual y por el cual ese objeto es. La expresión "metafisica de la subjetividad" indica no solo un período histórico de la filosofia, sino que condensa la crítica a la representación que estructura la realidad en torno a un yo objetivante y "cosas" que simplemente están-ahí, o-puestas y enfrentadas para ser captadas, inteligidas y significadas por el sujeto.

Uno y otro, sujeto y objeto, son: uno es conciencia intencional, otro es fenómeno. ¿Todo ello se observa en un "retroceso" a fondo hasta la "cosa misma"? ¿Entra en consideración del análisis fenomenológico la circunstancia de que "sujeto" y "objeto" presuponen el ser que son? ¿Ha procedido la fenomenología, en definitiva, de acuerdo a su propio principio de eliminar todos los prejuicios?

\section{La analitica del "hombre" como ex-sistencia}

Si pudiera hablarse - de una manera algo libre- acerca de una "esencia" 448 o "naturaleza" del hombre, entonces se podría afirmar que esta es, según Heidegger, la ex-sistencia. Se trata, claro está, de una forma figurada de expresarse, pues la ex-sistencia es precisamente la negación de una esencialidad o de una naturaleza fija. Es su relativización y su cuestionamiento por medio de

\footnotetext{
11 Rodríguez, R., Heidegger y la crisis de la época moderna, Madrid: Síntesis, 2006, p. 41.
} 
La superación de la metafisica de la subjetividad a través de una analitica de la coexistencia

la puesta en juego en-cada-caso y cada-vez que somos ${ }^{12}$. Jugada arriesgada y no garantizada por un substrato que permanecería inalterado a pesar de los múltiples avatares del existir. En este sentido debe interpretarse la tesis heideggeriana respecto de que la existencia precede a la esencia ${ }^{13}$.

Es oportuno puntualizar que son, por lo menos, tres los influjos que inciden decisivamente en la formación del pensar heideggeriano que conduce a la composición de Ser y tiempo ${ }^{14}$. Aquí solo puedo mencionar esas influencias y proponerlas como vias regias a seguir en una profundización ulterior. Tales influjos son los siguientes: la reflexión sobre el ser y la recuperación de la filosofia práctica de Aristóteles; la conciencia acerca de la facticidad histórica de la vida humana como ámbito originario (o pre-teórico) proveniente de los estudios heideggerianos tempranos sobre Dilthey, Kierkegaard y el cristianismo primitivo; y la investigación fenomenológica desarrollada por la filosofia de Husserl $^{15}$. Como anuncié al comienzo de este trabajo, de entre estas influencias me ocupo especialmente de la última, aunque me resulte inevitable en casos aludir parcialmente a las otras. Considerando esto, la interpretación que citaré extensamente a continuación condensa dos cuestiones fundamentales sobre las que es importante reflexionar: la relación Husserl-Heidegger en torno al significado de la fenomenología y -en sintonía con ello- las modificaciones y críticas de la subjetividad planteadas por Heidegger: "[e]1 revolucionario libro Ser y tiempo relega la fenomenología a la condición del método a aplicar a su tema,

12 Cf., Heidegger, M., Sein und Zeit, §25, p. 117; §42, p. 197; §43, p. 212.

13 Ibid., §9, pp. 42-43.

${ }^{14}$ Los tomos de las Obras completas (Gesamtausgabe = GA) que comenzaron a publicarse a través de la editorial Vittorio Klostermann (Fráncfort d.M.) en 1975, particularmente aquellos que recogen los primeros cursos de Freiburg y Marburg, permiten sostener que Ser y tiempo tiene una genealogia coherente y que no es un texto sin historia. Esos cursos no son solo preparatorios y pueden leerse como producciones autónomas. Sin embargo, representan a la vez la maduración progresiva de un tema y un modo de exposición que contribuyen a la producción de la obra de 1927.

15 Para una reconstrucción panorámica de estas influencias véase Rodríguez, R., Heidegger y la crisis de la época moderna, 2006, pp. 23-44. Otros muchos trabajos abordan separadamente los vínculos apuntados. Sobre la formación del pensamiento heideggeriano pueden consultarse disponibles en nuestro idioma- excelentes investigaciones. Refiero solo algunas de ellas: Pöggeler, O., El camino del pensar de Martin Heidegger, Madrid: Alianza Editorial, 1993; Rodríguez, R., La transformación hermenéutica de la fenomenología. Una interpretación de la obra temprana de Heidegger, Madrid: Tecnos, 1997; Safranski, R., Un maestro de Alemania. Martin Heidegger y su tiempo, Barcelona: Tusquets, 1997; Bech, J.M., De Husserl a Heidegger. La transformación del pensamiento fenomenológico, Barcelona: Edicions Universitat de Barcelona, 2001; Bertorello, A., "Método fenomenológico y narratividad", en: "I Jornadas de Literatura, Crítica y Medios", Buenos Aires, UCA/Facultad de Filosofia y Letras, 2003 (disponible en: bibliotecadigital.uca.edu.ar/repositorio/ponencias/metodofenomenologico-y-narratividad.pdf); Gadamer, H.-G., Los caminos de Heidegger, Barcelona: Herder. 2003; Volpi, F., Heidegger y Aristóteles, Buenos Aires: FCE, 2012. 
que es la ontología. Y si es correcto decir que Husserl inspiró aquí a Heidegger en lo que concierne al método, también lo es decir que fue Aristóteles quien lo inspiró en lo concerniente al tema. La fenomenología de Husserl era un análisis temático de la conciencia; la de Heidegger aspiraba al análisis temático del ser. Pero en ese análisis la pregunta general por el ser se veía, por así decirlo, retropropulsada a la pregunta por el ente o ser concreto que se la formula, que es el hombre, el cual no es visualizado meramente por Heidegger como un 'yo' cognoscente, ni tampoco como un mero 'animal racional', sino como un ser o ente que se encuentra arrojado a un mundo donde ha menester, como diría Ortega, de hacer su vida; o dicho en palabras de Heidegger, como un 'ser-enel-mundo', un ente que consiste, en suma, ser-ahí (Dasein)"16.

Parafraseando lo recién citado: el tema de la reflexión heideggeriana -el ser- proviene de Aristóteles y se aborda con recurso a un método que es el fenomenológico. Este método está inspirado en Husserl, pero Heidegger no repite su sentido, sino que se aparta de él en dos cuestiones centrales: (i) transforma hermenéuticamente la fenomenología; (ii) realiza un trabajo analitico previo a la tematización propiamente dicha del ser con el propósito de esclarecer quién y cómo es el ente que pregunta por el ser. Ese análisis implica dar cuenta de una instancia distinta a un yo teórico o a una conciencia trascendental. Se exige, en suma, no recaer en la metafísica de la subjetividad.

\subsection{La resignificación de la fenomenología como método}

De acuerdo con Heidegger, el tema eminente de la filosofia debe ser tematizado por principio como origen $(U r)$. El origen es una experiencia significativa. Se busca que esa significatividad resulte accesible y no quede encubierta, a contracorriente de la filosofia tradicional y de la metafisica de la subjetividad. El modo básico en que se expresa tal sentido originario es vida (Leben). Vida es Dasein, esto es: ejecución, concreción, realización, ex-sistencia. Ex-sistir es estar-fuera. Pero ese "estar" no es un mero "permanecer", sino un realizar-lavida. Ejecutar y realizar la vida es comprendido por Heidegger como cuidado 450 (Sorge).

Me parece posible sostener, entonces, que Heidegger se aparta de Husserl por su misma pretensión de seguirlo. Husserl afirmaba en el último párrafo de La filosofía como ciencia estricta: "[e]l incentivo para la investigación no tiene que

\footnotetext{
${ }^{16}$ Garrido, M., "Apéndice. Nota bio-bibliográfica", en: Heidegger, M., Tiempo y ser, Madrid: Tecnos, 2011, pp. 131-132.
} 
La superación de la metafisica de la subjetividad a través de una analitica de la coexistencia

provenir de las filosofias sino de las cosas y de los problemas. La filosofia es, sin embargo, por esencia la ciencia de los verdaderos principios, de los orígenes, de los rizomata panton [= las raíces de todo]. La ciencia de lo radical también tiene que ser radical en su proceder y desde todos los puntos de vista" ${ }^{17}$.

Esta pretensión de radicalidad -a saber, ir a las raíces de todo-Heidegger la asumió con resolución en su propia filosofia: la hizo equivalente al proyecto de investigar el origen, distinguiéndolo de lo derivado. Para tratar de capturar lo que esto quiere decir consideremos la siguiente pregunta: cuando intentamos determinar el sentido primero de un concepto, ¿nos es suficiente reparar en el uso que de ellos realizamos en la cotidianeidad o, por el contrario, ese uso encubre el sentido que buscamos? Podemos tener provisoriamente imprecisiones respecto de ese sentido primario buscado, pero avanzamos mucho desde el momento en que nos percatamos de que existen sentidos que -por habituales e institucionalizados que resulten- son secundarios o no originarios. La génesis de muchos términos y expresiones de la ciencia y de la filosofia muestra esta "lógica de la derivación" 18 .

De acuerdo a ello, la filosofia tiene que comprenderse como investigación del sentido originario y primero, de la instancia que todo otro sentido ya siempre presupone. Ese es el tema de una filosofia primera u ontología. Ella requiere un modo de acceso que permita la mostración de dicho origen y no contribuya a su ocultamiento identificando meras derivaciones. Por tanto, tema y método son interdependientes: este debe ser tal que no objetive o cosifique a aquel; aquel no se presenta sin este. ${ }^{19}$ Se trata de desarrollar una "fluidificación" de

\footnotetext{
17 Husserl, E., La filosofia, ciencia rigurosa, Madrid: Encuentro, 2009, p. 85.

${ }^{18}$ Los ejemplos son innumerables; basten aquí-a modo de ilustración- los siguientes dos tomados del habla cotidiano: (i) puede decirse “¡carajo!", entre otros sentidos, como interjección para significar decepción o asombro, o como insulto dirigido a otro; pero estos usos dejan enmascarado el hecho de que "carajo" es una parte de un barco de vela (el palo mayor) y que enviar a alguien a ese lugar era originariamente una reprimenda o sanción que podía recibir un marinero; (ii) la expresión "hacer un homenaje" se utiliza habitualmente para referir un acto de agasajo o remembranza respetuoso de una persona o situación, lo que supone una modificación (o derivación) importante respecto del momento de la ceremonia en la cual -durante el llamado medioevo- se instituía un vasallaje: el homenaje era originariamente un juramento que legitimaba prácticas de sumisión, veneración y respeto, desarrollado precisamente en la "torre de homenaje" del castillo, donde el vasallo se comprometía ante libros sagrados y ante su señor, haciéndose propiedad de este.

${ }^{19}$ Sin embargo, aunque los discursos disponibles (especialmente las maneras de hablar de la filosofia tradicional y de las epistemologías de las diversas disciplinas) tienen una pretensión aclaratoria, culminan distanciando, escamoteando y camuflando el origen. Por ello, "Heidegger pregunta: ¿cómo experimentamos la realidad antes de organizarla con la actitud de la ciencia, o de los valores, o de una concepción del mundo? A esta ciencia de la ciencia no le da el nombre de teoría de la ciencia, sino [hacia 1919-1920] el de La idea de la filosofía como ciencia originaria" (Safranski, R., Un maestro de Alemania. Martin Heidegger y su tiempo, p. 123).
} 
la tradición metafísica, un agrietamiento de esta, de sus cánones y definiciones incuestionadas ${ }^{20}$.

Este origen no es algo así como la fuente de validez del conocimiento -a la manera de la función que cumple la evidencia en Descartes, la concordancia entre impresión e idea en Hume o las condiciones trascendentales de la razón pura en Kant-, sino algo más fundamental (es fundamento), principal (se encuentra al principio) y básico (está a la base): es decir, es la fuente de sentido de las cosas y de nuestra propia existencia. El joven Heidegger (especialmente el de la primera estancia en Freiburg [1916-1923]), próximo al lenguaje de la filosofia vitalista por entonces en auge y, en particular, al pensamiento de Dilthey, concebirá al origen como vida. La vida constituye una esfera completamente opuesta a la de la teoría y la objetivación, por lo que no puede abordarse de acuerdo al pensamiento representativo que -en sintonía con la "metafísica de la subjetividad" - privilegia la relación epistémica entre un yo cognoscente y la realidad. Vida en Heidegger es abreviatura de experiencia-fáctica-de-la-vida y el "sujeto" de esta experiencia es un "yo" histórico y situado (no sustancial, ni trascendental, ni espiritual). El modo más rotundo en que Heidegger se refiere a esta instancia originaria es el siguiente: "Vida = Dasein, 'ser' en y a través de la vida" ${ }^{21}$.

Esta virtual "ecuación" o equivalencia nos adelanta algo muy importante: que el proyecto consistente en preparar y clarificar la cuestión ontológica decisiva, la del ser, requiere la aclaración y la analítica del ente que interroga por el ser, y que ya aquí (el extracto corresponde a un curso dictado por Heidegger en 1921/1922) ha sido presentado como Dasein. Repárese en el "en" y en el "a través" de la expresión citada para ver allí que la vida no es algo estático, conquistado y disponible desde siempre y para siempre, sino que ella es dinámica, movimiento, realización, ejecución. Se es la vida en y a través de la vida, es decir, existiendo.

Por su parte, la filosofia teorética y objetivadora no puede captar ese flujo vital. Al contrario, lo cristaliza. Frente a la relación epistémica sujeto-objeto (metafísica de la subjetividad), la reflexión heideggeriana privilegia la relación

\footnotetext{
${ }^{20}$ Heidegger, M., Sein und Zeit, §6, p. 22. Como apunta Gadamer, destrucción comporta "el decidido desmontaje de las capas sobrepuestas, para volver desde la terminología dominante a la experiencia originaria del pensamiento... En contra de todas las pretensiones de un lenguaje conceptual propio, él mismo [Heidegger] usaba con preferencia la expresión 'indicación formal"' (Gadamer, H.-G., Los caminos de Heidegger, p. 353).

21 Heidegger, M., Phänomenologische Interpretationen zu Aristoteles. Einführung in die phänomenologische Forschung, Fráncfort d.M.: Vittorio Klostermann, 1985, p. 85.
} 
existencial sujeto-sujeto (filosofia de la intersubjetividad) en la que nada queda definido a priori, sino a través del ejercicio y la realización, de la puesta en juego de cada vida frente a otra vida. Éste es el fenómeno originario (Urphänomen): "La vida humana es una instancia última e irrebasable.. De ahí la necesidad de emprender una destrucción de los estereotipos transmitidos, de iniciar un desmontaje de las diferentes capas interpretativas que enmascaran la auténtica y genuina faz del fenómeno de la vida"22.

Una cuestión relevante en este punto viene dada por el hecho de que Heidegger entiende -inspirado en Dilthey- que la vida tiene una significatividad propia, esto es, posee carácter semántico. El sentido y la significatividad son anteriores a su expresión conceptual. Incluso, "a las significaciones les brotan palabras, en vez de ser las palabras las que, entendidas como cosas, se ven provistas de significaciones" 23 . No hay primero "cosas" ("externas", como sillas, mesas, ventanas, etcétera, o "interiores", como sentimientos o fantasías) a las que luego les añadimos (les "pegamos") un rótulo que las identifica y una función que les da sentido. Lo primero es la significatividad. Es lo más patente, aquello en lo que estamos involucrados ya siempre, aunque no nos percatemos. Por eso Heidegger sostiene: "viviendo en un mundo circundante, me encuentro rodeado siempre y por doquier de significados, todo es mundano, 'mundea' [es weltet]..."

Ese "mundear" (neologismo inventado por Heidegger) es aquello que por su proximidad no advertimos: se trata, como queda dicho, del sentido original, inicial y primero, ciertamente difuso y borroso, pero anterior a cualquier representación que nos hacemos de él. Es lo que en esta época Heidegger llama "actitud originaria de la vivencia", "intención originaria de la vida vivida" o simplemente "vivencia originaria".

Vemos entonces que Heidegger comparte el propósito fenomenológico de "ir a las cosas mismas" y de encontrar las "raices de todo", pero -a diferencia de Husserl- esa "cosa" y esa "raíz" no son ya un contenido conciencial ("lo mentado en tanto que puramente mentado"), sino sentido y significación. Ahora bien, ¿qué relación guarda "el hombre" con esa significatividad originaria, es decir, con el hecho de que la vida sea sentido ${ }^{25}$. Heidegger subraya desde sus

\footnotetext{
${ }^{22}$ Escudero, J.A., "Prólogo": en Heidegger, M., Interpretaciones fenomenológicas sobre Aristóteles, Madrid: Trotta, 2002, pp. 20-21.

${ }^{23}$ Heidegger, M., Sein und Zeit, §34, p. 161.

${ }^{24}$ Heidegger, M., La idea de la filosofia y el problema de la concepción del mundo, Barcelona: Herder, 2005, p. 88.

25 A pesar de los momentos en que dividí mi exposición, lo que digo a continuación puede considerarse sin dudas como un adelanto de lo que abordaré en el siguiente apartado de este trabajo.
} 
escritos iniciales la condición realizativa del "individuo" -que prefigura lo que en Ser y tiempo denominará cuidado [Sorge] -. Porque ya siempre tratamos con, en y desde el mundo, no cabe, en rigor, decir que se trata de una "actitud" o "posición" que se asuma o llegue a asumir, sino que invariablemente existimos con-en-desde el mundo. Estar-en-el-mundo es estar-en-trato-con-el-mundo, realizando algo con-en-desde él. En efecto, así como la intencionalidad husserliana comportaba una relación predominantemente teorética ante el mundo (como conciencia-de), en el caso de Heidegger el vínculo del "hombre" con el mundo es pragmático. Lo es de triple manera: en su trato con el mundo-entorno o circundante (Umwelt); en su trato con el mundo compartido con otros (Mitwelt); y en su trato con el mundo propio (Selbstwelt). Debe notarse bien: no son "tres" mundos distintos y separados, sino uno y el mismo articulado cooriginariamente de triple forma. Esta "posición" realizativa, comportamental o pragmática del "hombre" implica que el predominio lo tiene el yo soy, no el yo pienso.

Ahora bien, la vida (o: el fenómeno originario) es hermenéutica. La hermenéutica filosófica prolonga esa condición estructural: ex-pone y aclara el sentido del ser. La vida vivida y el mundo que "mundea" se encuentran siempre en estado-interpretativo (Ausgelegtheit). Heidegger afirma: "En él, desde él y contra él se lleva acabo toda genuina comprensión, interpretación y comunicación, todo redescubrimiento y toda reapropiación" ${ }^{26}$. Heidegger sostendrá que la vida fáctica es comprendida (o interpretada) inmediatamente de manera desfigurada. A pesar del carácter inobjetivo ${ }^{27}$ de la vida, habitual y cotidianamente tenemos una propensión a caer en las significaciones objetivas para captarla. No se trata de una experiencia circunstancial o pasajera, sino de una parte constitutiva de la facticidad. Una de las consecuencias de ello es que, en tal caída (Verfallen), el "hombre" tiende a comprenderse como un ente que él no es. Dicho caer se convierte en un extravío o una pérdida de sí mismo. En este sentido, "[1]a hermenéutica tiene la labor de hacer el existir propio de cada momento accesible en su carácter de ser al existir mismo, de comunicárselo, de tratar de aclarar esa alienación de sí mismo [Selbstentfremdung] de que está afectado el existir" ${ }^{28}$.

\footnotetext{
${ }^{26}$ Heidegger, M., Sein und Zeit, §35, p. 169.

${ }^{27}$ Rodríguez, R., Heidegger y la crisis de la época moderna, 2006.

${ }^{28}$ Heidegger, M., Ontologie (Hermeneutik der Faktizität), Fráncfort d.M.: Vittorio Klostermann, GA 63, 1982, §3, p. 15.
} 
Insisto: la hermenéutica filosófica es la extensión de la condición hermenéutica que ya tiene el existir. Lo que esa prolongación pretende es introducir algo así como un contramovimiento respecto del encubrimiento de la caída. Entonces, este es el inicio metodológico de Heidegger: la orientación previa (hacia el ser), la precomprensión (del ser). Cuando desde allí queremos ex-traer, ex-poner lo precomprendido para comprenderlo cabalmente en su sentido, entonces la circularidad no es un defecto lógico, sino, al contrario, algo que abre un vasto campo de investigación disponible respecto del ser. La circularidad lógica es demostrativa; el círculo hermenéutico o de la comprensión es mostrativo. Desde la precomprensión vaga e indeterminada intenta sacar a luz, aclarar, explicitar una auténtica comprensión. De acuerdo a esto, "[e]1 modo de acceso y de interpretación debe ser escogido... de tal manera que este ente se pueda mostrar en sí mismo y desde sí mismo. Y esto quiere decir que el ente deberá mostrarse tal como es inmediata y regularmente en su cotidianidad media" ${ }^{29}$.

En una cita precedente recordé que Heidegger dedica un parágrafo de Ser y tiempo a elucidar en qué consiste el método fenomenológico de la investigación que empleará. Alli "fenomenología" no es simplemente una corriente filosófica o un punto de vista: ella "no caracterizará el qué de los objetos de la investigación filosófica, sino el cómo de esta” ${ }^{30}$. Fenomenología no es una perspectiva externa respecto de un tema determinado, a la manera de una cienciade los fenómenos (como se dice también que la psico-logía es la ciencia-de la psiquis; o la socio-logía es la ciencia-de lo social; o la teología la ciencia-de lo divino; etcétera). Si así fuera, el tema en cuestión culminaría objetivándose y cosificándose.

Fenómeno (phainómenon) es lo-que-se-muestra. Justamente por esto cabe la posibilidad de que el ente se muestre como lo que él no es. Ahora bien, esta mostración o apariencia -sea o no distorsionada- no es "mera manifestación" de un trasfondo que sería para nosotros inalcanzable, como el noúmeno kantiano. Más bien, según afirma Heidegger, "encubrimiento es el contraconcepto de 'fenómeno" ${ }^{31}$.

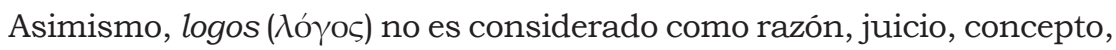
definición, fundamento o relación, sino, ante todo, como "decir" (Rede) o "hacer ver mediante el lenguaje". Heidegger quiere subrayar el carácter mostrativo

${ }^{29}$ Heidegger, M., Sein und Zeit, §5, p. 16.

30 Ibid., §7, p. 27.

31 Ibid., §7, p. 36. 
(apofántico) del $\operatorname{logos}^{32}$. Poner algo en logos es hacerlo patente, mostrarlo y ex-ponerlo. Solo por esto el logos puede ser verdadero o falso. Verdad aquí no es concordancia o adecuación entre la cosa y el pensamiento, sino $\alpha \lambda \lambda \dot{\eta} \theta \varepsilon\llcorner\alpha$ (aletheia): sacar de su ocultamiento al ente del que se habla. Como concepto preliminar de la fenomenología, Heidegger revitaliza la máxima de Husserl " $¡ a$ las cosas mismas!". Esto afecta directa y principalmente al concepto de fenómeno y al tipo de investigación a emprender. Veamos: “¿A qué se debe llamar 'fenómeno' en un sentido eminente? ¿Qué es lo que por esencia necesariamente debe ser tema de una mostración explícita? Evidentemente, aquello que de un modo inmediato y regular precisamente no se muestra, aquello que queda oculto en lo que inmediata y regularmente se muestra, pero que al mismo tiempo es algo que pertenece esencialmente a lo que inmediata y regularmente se muestra, hasta el punto de constituir su sentido y fundamento. Ahora bien, aquello que eminentemente permanece oculto o recae de nuevo en el encubrimiento, o solo se muestra 'disimulado', no es este o aquel ente, sino, como lo han mostrado las consideraciones anteriores, el ser del ente" ${ }^{33}$.

Ahora resulta evidente que la investigación de Heidegger -como ontología fundamental, es decir, como tematización del ser- comporte necesariamente el trabajo de desmontar encubrimientos ${ }^{34}$. Son insistentes las advertencias acerca de que debemos precavernos de tomar como verdadero lo que ya está disponible, especialmente lo que se ha validado por medio del lenguaje de la tradición filosófica. Recordemos: aquello de lo que nos queremos ocupar se expresa por medio del logos. Esa expresión puede consistir en un encubrimiento, en lugar de realizarse como un auténtico mostrar. Es lo que de hecho ha sucedido -piensa Heidegger- en el lenguaje de la filosofia moderna. ¿Cómo se ex-pone el ser allí? Como sujeto. La ontología hermenéutica desarrollada en Ser y tiempo quiere desmontar y destruir esa comprensión pues encubre, y no muestra, el fenómeno básico: la vida como coexistencia.

\subsection{El ente que interroga por el ser}

456 Sujeto es encubrimiento del Dasein. Este encubrimiento es correspondiente a un olvido en torno a la cuestión del ser. Para recuperar esta problemática

\footnotetext{
${ }^{32}$ No se trata simplemente de "discurso", pues esto refiere solamente la articulación (el dis-currir) en que se pasa de una cosa a otra.

${ }^{33}$ Heidegger, M., Sein und Zeit, §7, p. 35.

${ }^{34}$ Heidegger, M., Prolegómenos para una historia del concepto de tiempo, Madrid: Alianza Editorial, 2006, p. 116.
} 
fundamental (ontológica) debe llevarse a cabo previamente una analítica del ente que interroga por el ser. Ese ente es, precisamente, Dasein. El Dasein es de un modo diferente a como es cualquier otro ente, a saber: solo él ex-siste. Pero -permítaseme el juego de palabras- no existe solo: Dasein es (co)ex-sistencia. (Co)ex-sistencia es praxis abierta, aquí y ahora, con otros co-existentes.

¿De qué modo encubre el sujeto? ¿Por qué "sujeto" es contrario a Dasein? El sujeto es una creación artificiosa, inventada y forzada, al ser postulada con independencia de la facticidad. Solo por medio de esta exención de la vida fáctica la filosofia ha podido presentar al sujeto como criterio de certeza última, de evidencia y de apodicticidad: "en la actitud 'objetivante de la ciencia' hacemos que desaparezca la significatividad primaria, lo relativo al 'mundo circundante', lo vivencial, desvestimos el algo hasta su objetividad 'desnuda', cosa que solo se logra por el hecho de que también dejamos fuera el yo que experimenta la vivencia y establecemos un yo artificial, secundario, que es bautizado con el nombre de 'sujeto'... [Al contrario], la situación originaria no comienza así. Comienza, más bien, con el hecho de que nosotros nos encontramos bajo la descrita forma mundeante en el mundo...”"

Esta forma "mundeante" del carácter ejecutivo, realizativo o comportamental que "el hombre" tiene respecto del mundo (triplemente articulado: circundante, compartido y de sí) es lo que queda encubierto por la metafísica de la subjetividad.

En el programa filosófico planteado en Ser y tiempo en torno a la cuestión del ser, la analítica del ente que interroga por él hace posible la ontología misma: la pregunta por el ser no la plantea una casa o un animal; solo el hombre puede formularla debido a que entre todos los entes él es el ahi del $\operatorname{ser}^{36}$. En efecto, literalmente, Da-sein significa ser (sein) ahí (da). Ofrece un "lugar", una "residencia" al ser, albergándolo como tarea, perola pregunta por el ser ha caído en el olvido. Nos hemos acostumbrado a investigar lo que los entes son, sin esclarecer qué significa el simple y profundo hecho de ser. Este ser es lo que cualquier ente ya siempre presupone, sin reducirse a él: el ser del ente, por tanto, no es un ente ${ }^{37}$. Que el ser sea el tema de la ontología heideggeriana no implica que trate de aquello que primera e inmediatamente

\footnotetext{
35 Safranski, R., Un maestro de Alemania. Martin Heidegger y su tiempo, pp. 126-127.

${ }^{36}$ Cf., Löwith, K., Heidegger, pensador de un tiempo indigente. Sobre la posición de la filosofia en el siglo XX, Buenos Aires: FCE. 2006, pp. 133-134.

37 Esto es lo que será comprendido por Heidegger como diferencia ontológica: ella alude, simplemente, al hecho de que el ser no es el ente. Hay entes que son meras "cosas", otros que sirven para... y otros que son Dasein. Todos ellos "son" (entes); pero eso que "son" puede y debe diferen-
} 
se tematiza y expone. En efecto, "elaborar la pregunta por el ser significa hacer que un ente - el que pregunta- se vuelva transparente en su ser... A este ente que somos en cada caso nosotros mismos, y que, entre otras cosas, tiene esa posibilidad de ser que es el preguntar, lo designamos con el término Dasein. El planteamiento explícito y transparente de la pregunta por el sentido del ser exige la previa y adecuada exposición de un ente (del Dasein) en lo que respecta a su ser, ${ }^{38}$.

Nótese cómo en su planteo Heidegger nos conduce de una relación de equivalencia a una relación de determinación: primero, preguntar por el ser significa hacer transparente al ente que pregunta; al final, preguntar por el ser exige -y, por esto, depende de- el hacer transparente a quien interroga. La exposición previa requerida es lo que Heidegger denomina "analítica ontológica del Dasein". Su desarrollo constituye una consumación nítida del apartamiento de la metafísica de la subjetividad. Por medio de ella, se demuestra que el "yo soy" o "yo existo" está presupuesto, aunque no tematizado, en el "yo pienso": "la existencia... puede ser entendida como una forma de ser, como un determinado sentido del 'es', el esencial 'es' del 'yo soy"39.

Sabemos ya que la vida da testimonio de sí misma por su estructura hermenéutica y que no está allí originariamente como sierva de quien la investiga, preparándose para ser teorizada u objetivada. Con "da testimonio sí misma" quiero decir: se expresa, se manifiesta, incluso se comporta, siempre antes de la mirada del contemplador (científico o filosófico). El comportamiento es un modo de ser. El modo de ser no viene dado con independencia del movimiento de la vida, sino que es el modo en que ella se asume. Se es Dasein en-cada-caso o cada-vez. Ahora bien, ¿cómo saber acerca de ese modo de testimoniarse? Esta empresa no puede resolverse "desde fuera", con teorías y métodos ajenos, pues así construiriamos un discurso objetivante y por tanto derivado. Se trata de alcanzar el "origen". Heidegger afirma que esto es viable pues hay un ente particularísimo que ya posee una precomprensión del ser. Vale decir: hay un ente que nos ofrece un hilo conductor privilegiado en nuestro camino hacia el ser como origen.

ciarse del ser. El Dasein es el único ente que pre-comprende el ser y por ello se realiza un análisis de él en Ser y tiempo (es su "hilo conductor privilegiado") como etapa preparatoria.

${ }^{38}$ Heidegger, M., Sein und Zeit, §2, p. 7. Los subrayados me pertenecen.

${ }^{39}$ Heidegger, M., Anmerkungen zu Karl Jaspers 'Psychologie der Weltanschauungen', en: Wegmarken, Fráncfort d.M.: Vittorio Klostermann, GA 9, 1979, p. 79. 
Es la praxis la que revela o muestra al Dasein cómo es él, cómo le va el ser. En el texto heideggeriano el cómo (Wie) aparece concretado como cuidado (Sorge) por nuestro ser. En esto tenemos dos posibilidades: la propiedad (eigentlich) o la impropiedad (uneigentlich). Lo propio es del todo dependiente de la asunción de nuestro ser finito, del encuentro con nuestro ser-para-la-muerte en tanto, justamente, la muerte es nuestra posibilidad más propia e intransferible. Se trata de un cómo (Wie) vivencial, histórico, fáctico, en suma, de un ser-en-el-tiempo. Que somos libres para resolvernos por este modo de ser nos lo puede revelar la angustia. Sin embargo, la posibilidad impropia es también una posibilidad nuestra: algo que nos damos (paradojalmente como pérdida, huida o esquivamiento). Por ello se muestra en un tipo o modo de ser caído, sumergido en el torbellino donde se es, se dice y se hace... tal como se es, se dice y se hace im-personalmente. Heidegger llama a esto das Man, "el uno", que significa anonimato, nadie, todos y ninguno a la vez.

El cómo (Wie) será el horizonte desde el cual se interrogará al ser-enel-mundo, al yo soy. La investigación preguntará por posibilidades nuestras, que nos damos (nosotros, wir) históricamente (ahora, jeweilig) en el mundo en tanto allí (ahí, da). Allí precisamente ponemos en juego nuestra existencia: la existencia consiste en un pro-iectum arriesgado. Es movimiento y dinámica. El "hombre" se comprende de este modo como instancia fáctica, histórica, temporal. ¿Cómo (Wie) es el Dasein?: es lo que hace consigo mismo en su vida, de acuerdo a cómo se realiza frente al qué de los contenidos ${ }^{40}$. En la vida misma, en la existencia, se encuentra disponible una interpretación intersubjetivamente compartida, pre-teórica, previa al discurso objetivante de la ciencia. La vida humana parte de esta anterioridad significativa del sentido del mundo. La filosofia es ontología fenomenológica en la medida en que se ocupa del darse el obrar humano (Dasein), es decir, de su modo (Wie) de relacionarse práctico con los entes, consigo mismo y con otros Dasein.

La vida es, como origen, movimiento. El Dasein es quien se mueve, coexistiendo. En rigor, el Dasein no tiene definición, pues posee la condición de lo inacabado, en tanto su ser es tarea, praxis, proyecto. Esa realización (la ejecución, la facticidad del Dasein) está habitual y regularmente encubierta y distorsionada.

\footnotetext{
${ }^{40}$ Interpelar “¿cómo es el Dasein?” y no “¿qué es el Dasein?” pretende evitar todo "sustancialismo" o "esencialismo", pues la respuesta a la segunda pregunta ha conducido inevitablemente a la postulación de un "algo" permanente, idéntico a sí mismo, conquistado antes y con independencia de la praxis.
} 


\section{La analitica como co-ex-sistencia}

Ser es ex-sistir. Pero ex-sistir es co-ex-sistir. El "otro" no es un añadido. Co-ex-sistimos en un mundo compartido. La co-ex-sistencia está dada habitual y regularmente en un modo impropio. Al co-ex-sistir impropiamente el Dasein vive en el anonimato. El anonimato expresa el ser caído de la co-ex-sistencia. La caída tiene sus propios modos de ser. Por ello, en el trato con los "otros" pueden ser identificadas y tematizadas formas deficientes. La propiedad es una modificación existencial.

En diversos lugares de Ser y tiempo Heidegger distingue su propio discurso de los presupuestos y ambiciones de la psicología, la biología, la etnología, la antropología y las ciencias del espíritu en general. A manera de ejemplo, inmediatamente antes de emprender el estudio de los modos en que queda abierto "el uno" (das Man) en la cotidianidad, afirma: "la interpretación [a saber: la interpretación que Ser y tiempo ofrecerá] tiene un propósito puramente ontológico, y... está muy lejos de una crítica moralizante del Dasein cotidiano y de cualquier tipo de aspiraciones propias de una filosofia de la cultura”" ${ }^{41}$. Esta analítica la realiza "en base a algunos fenómenos particulares" "42 que expresan el modo de ser cotidiano del discurso, la visión y la interpretación (a saber: la habladuría, la curiosidad y la ambigüedad).

Como he planteado antes, la pregunta por el quién de la cotidianidad no puede responderse sin plantear al mismo tiempo la correspondiente interrogación sobre cómo está-en-el-mundo ese quien. Ahora puede ser subrayada y abordada con profundidad la circunstancia de que "la aclaración del estar-enel-mundo ha mostrado que no 'hay' inmediatamente ni jamás está dado un mero sujeto sin mundo. Y de igual modo, en definitiva, tampoco se da en forma inmediata un yo aislado sin los otros... La tarea consiste en aclarar la índole de esta coexistencia [Mitdasein] en la inmediata cotidianidad..." . Aquí la "indole" quiere decir: el modo (cómo) inmediato y regular de ser-con. El Dasein es estructuralmente ya siempre un estar-en-el-mundo, donde estar es coestar (Mitsein) y mundo es mundo en común (Mitwelt). Todo esto cobra centralidad en Ser y tiempo a partir del Capítulo IV de la primera sección. Sin embargo, el orden expositivo no afecta la originariedad de lo expuesto. Como ya indiqué, Heidegger señala con insistencia que los existenciales (o existenciarios) que forman parte del todo estructural que la obra analiza son igualmente cooriginarios. Por ello

41 Heidegger, M., Sein und Zeit, §34, p. 167.

42 Ibid.

${ }^{43}$ Ibid., §25, p. 116. 
creo posible y justificado inscribir a este momento de Heidegger en la llamada "filosofia de la intersubjetividad".

La "cotidianidad" del quien remite a su darse ya siempre en una comunidad social y política, o-como Heidegger mismo dice- "en una cultura altamente desarrollada y diferenciada" ${ }^{44}$. Es evidente que el darse en cuestión está situado. El mostrarse del ser del Dasein, su entidad, concreta en-cada-caso las indicaciones formales que son explicitadas por medio del análisis de la coexistencia. Aquí no se trata, como en Hegel, de aclarar una experiencia del quién "genética" (en referencia, por ejemplo, a la emergencia de la autoconciencia por medio de la experiencia de la lucha a vida o muerte por el reconocimiento). Comparativamente, la analitica heideggeriana, ofrece un estudio acerca de la concreción cotidiana y fáctica del modo de ser que pone en juego ese quién ${ }^{45}$. Ahora bien, "paradójicamente", el quién concreto cotidiano es Nadie: "El quién no es este ni aquel, no es uno mismo, ni algunos, ni la suma de todos. El 'quién' es el impersonal, el 'se' o el 'uno' [das Man]... En la cotidianidad del Dasein la mayor parte de las cosas son hechas por alguien de quien tenemos que decir que no fue nadie... Esta manera de ser no significa un menoscabo de la facticidad del Dasein...”. No es una "nada" puesto que ese Nadie $^{47}$ se determina en la cotidianidad como habladuría, curiosidad y ambigüedad. Notemos aquí dos cuestiones: primero, siendo el uno dominio (Botmäßigkeit) y dictadura (Diktatur), Heidegger admite que los modos en que se actualiza ese imperio (su fuerza e intensidad) "pueden variar históricamente" ${ }^{48}$. De hecho, tiene lugar esta variación siempre, tanto por las referencias con que Heidegger caracteriza la tentación y la tranquilización que provee la caída (periódicos, medios de comunicación, tipos de herramientas, artefactos, etcétera), como por la reiterada circunstancia del en-cada-caso y cada-vez. Segunda cuestión: se impone esclarecer cómo ha de ser posible pensar la co-ex-sistencia cuando el quién, sin ser nada, es sin embargo impersonal, Nadie.

El Dasein es pragmático porque ya siempre se comporta y está inexorablemente en un determinado quehacer; porque en definitiva, lleva a cabo el cuidado

\footnotetext{
44 Ibid., $§ 11$, p. 50.

${ }^{45}$ Cf. Bertorello, A., "Método fenomenológico y narratividad".

46 Heidegger, M., Sein und Zeit, §27, p. 126.

47 "Nadie" expresa el carácter del "sujeto" de la cotidianidad, del quién en su caída. Para que no quepan dudas acerca de esto, Heidegger escribe en varios lugares de Sein und Zeit (\$§ 27, 38, $51,54,57)$ tal expresión con mayúsculas (al modo de un sustantivo propio). En la traducción de Rivera (Heidegger, M., Ser y tiempo, Madrid: Trotta, 2006) solo se conserva la sustantivación producida en el $\$ 54$.

48Heidegger, M., Sein und Zeit, §27, p. 126.
} 
(Sorge) de su existencia. Tal comportamiento es ocupación (Besorgen) respecto de útiles a la mano (o "herramientas", cuyo ser consiste en su servicialidad) y solicitud (Fürsorge) respecto de otros Dasein. Este último existencial tiene el significado de una interpelación de los coexistentes: ya siempre nos preocupamos, nos inquietamos, somos movilizados y solicitados por los demás. No quiere decir que estoy en soledad y "aparece" otro con quien puedo circunstancialmente "empatizar" o no. De ninguna manera se trata de un estado psicológico que pueda o no tener. Solicitud es -en términos fenomenológicos-intencionalidad de los Dasein entre sí. Intencionalidad de Dasein a Dasein. Ahora bien, inmediata y regularmente, el Dasein se mueve en modos deficientes de la solicitud: "Ser uno para otro, estar uno contra otro, prescindir los unos de los otros, pasar el uno al lado del otro, no interesarse los unos por los otros, son modos posibles de la solicitud. Y precisamente los modos de la deficiencia y la indiferencia, mencionados al final, caracterizan el convivir cotidiano y de término medio" ${ }^{49}$.

Como mencioné antes, en el modo de ser impropio no dejo de determinar mi existencia, es decir, no dejo de concretarme como Nadie. Nadie es mutualidad y reciprocidad, pero no del reconocimiento, sino de la impropiedad. Nadie es el dominio de la publicidad en la interpretación de la solicitud. Nadie no es un tercero distinto de mis posibilidades y de las de otro. De acuerdo a esto, Nadie soy yo y el otro despotenciados, irresolutos y anónimos. Heidegger dice: "inmediatamente yo no 'soy' 'yo', en el sentido del propio sí-mismo, sino que soy los otros a la manera del uno" ${ }^{\text {"50 }}$. Esta manera, este modo de concretar mi existencia, es ser Nadie. Indica la deserción y la entrega de mi propiedad y, por esto mismo, la admisión de mi reemplazabilidad por cualquiera. En el modo del Nadie no solo no puede recibirse reconocimiento como coexistente, sino que tampoco puede plantearse una auténtica demanda del "otro" concreto. Lo que se verifica es, más bien, una exigencia sorda e incansable, el poder arbitrario y tiránico del das Man.

Lo dicho implica la realidad de un especial tipo de lucha. En ella lo que se dirime no es la vida o la muerte (como sucedía en Hegel), sino la existencia propia o la existencia impropia. Por ello Heidegger afirmó respecto del estado interpretativo que "en él, desde él y contra él se lleva a cabo toda genuina comprensión, interpretación y comunicación”, como señalé antes ${ }^{51}$. Ahora bien,

\footnotetext{
49 Ibid., §26, p. 121.

50 Ibid., §27, p. 129.

51 En el mismo sentido: "El absorberse en el uno significa el dominio del estado interpretativo público. Lo descubierto y abierto lo está en el modo del disimulo y de la obstrucción que resultan
} 
La superación de la metafisica de la subjetividad a través de una analitica de la coexistencia

la propiedad no remite a una alteridad absoluta respecto de lo que inmediata, regular y concretamente soy, sino a la apropiación y reapropiación de la misma impropiedad, cumpliendo así una auténtica transformación co-existencial.

\section{Comentario final}

He pretendido mostrar los trazos fundamentales en que se lleva a cabo la superación de la metafísica de la subjetividad a través de una analítica de la coexistencia. La transformación hermenéutica de la fenomenología -que está a la base de dicha superación- tiene para nosotros alguna relevancia si: por un lado, no perdemos de vista la recepción y lectura heideggeriana de Husserl, focalizada sobre todo en las implicancias de la "reducción" de acuerdo a las formulaciones de Ideas I es decir, tal como fue expuesta hacia 1900, en detrimento de otras reflexiones posteriores ${ }^{52}$; por otro, recortamos el programa ontológico formulado en Ser y tiempo (cuyo plan es expuesto en el §8) a su fase analítica previa, tal como fue desarrollada en la parte publicada de la obra. En el marco que así resulta encontramos la posibilidad de considerar la relación crítica Husserl/Heidegger como uno de los modos en que se lleva a cabo la deconstrucción del sujeto moderno. La idea de que ya siempre co-pertenecemos a un mundo compartido, que cada-vez nuestra existencia (Dasein) se juega y resuelve de acuerdo al modo en que se ejecuta nuestra co-existencia (Mitsasein), coloca la reflexión en un registro diferente al que se inicia con un sujeto a partir del cual la comunidad es evidenciada y explicada. Según esto, y considerando los términos que son puestos en cuestión, el pensar temprano de Heidegger puede ser considerado como una "filosofia de la intersubjetividad".

Recibido: $14 / 02 / 2019$

Aceptado: 13/07/2020

\footnotetext{
de la habladuria, la curiosidad y la ambigüedad... De ahí que el Dasein tenga también la esencial necesidad de apropiarse explícitamente de lo ya descubierto, en lucha contra la apariencia y la disimulación [gegen den Schein und Verstellung], y la de asegurarse siempre de nuevo del estar al descubierto" (Ibid., §44, p. 222; subrayado en el original).

${ }^{52}$ Me refiero a los trabajos incluidos en Husserliana titulados Zur Phänomenologie der Intersubjektivität. Texte aus dem Nachlass y ya referidos en la nota 3. El texto de 1936, casi 10 años posterior a Sein und Zeit, denominado Die Krisis der europäischen Wissenschaften und die transzendentale Phänomenologie. Eine Einleitung in die phänomenologische Philosophie confirma la preocupación de Husserl por dar cuenta de la inscripción del ego en una comunidad (aquí, especialmente al hilo del concepto Lebenswelt).
} 


\section{Bibliografia}

Bech, J.M., De Husserl a Heidegger. La transformación del pensamiento fenomenológico, Barcelona: Edicions Universitat de Barcelona, 2001.

Bertorello, A., "Método fenomenológico y narratividad", en: "I Jornadas de Literatura, Crítica y Medios", Buenos Aires, UCA, Facultad de Filosofia y Letras. Consultado: 10/01/2018. URL: bibliotecadigital.uca.edu.ar/repositorio/ponencias/metodofenomenologico-y-narratividad.pdf, 2003.

Escudero, J.A., "Prólogo", en: Heidegger, M., Interpretaciones fenomenológicas sobre Aristóteles, Madrid: Trotta, 2002, pp. 9-23.

Gadamer, H.-G., Los caminos de Heidegger, Barcelona: Herder, 2003.

Garrido, M., “Apéndice. Nota bio-bibliográfica”, en: Heidegger, M., Tiempo y ser, Madrid: Tecnos, 2011, pp. 127-156.

Heidegger, M., Anmerkungen zu Karl Jaspers 'Psychologie der Weltanschauungen', en: Wegmarken, Fráncfort d.M.: Vittorio Klostermann, GA 9, 1979, pp. 1-44.

Heidegger, M., Ontologie (Hermeneutik der Faktizität), Fráncfort d.M.: Vittorio Klostermann. GA 63, 1982.

Heidegger, M., Phänomenologische Interpretationen zu Aristoteles. Einführung in die phänomenologische Forschung, Fráncfort d.M.: Vittorio Klostermann. 1985.

Heidegger, M., Nietzsche, v. II, Barcelona: Destino 2000.

Heidegger, M., Sein und Zeit, Tubinga: Max Niemeyer Verlag, 2002.

Heidegger, M., La idea de la filosofía y el problema de la concepción del mundo, Barcelona: Herder. 2005.

Heidegger, M., Ser y tiempo, Madrid: Trotta, 2006.

Heidegger, M., Prolegómenos para una historia del concepto de tiempo, Madrid: Alianza Editorial, 2006.

Heidegger, M., "Mi camino en la fenomenología”, en: Tiempo y ser, Madrid: Tecnos, 2011, pp. 95-103.

Heidegger, M., "La época de la imagen del mundo", en: Caminos de bosque, Madrid: Alianza Editorial, 2012, pp. 63-90.

Husserl, E., Ideas relativas a una fenomenología pura y una filosofía fenomenológica, México: FCE, 1962.

Husserl, E., La filosofia, ciencia rigurosa, Madrid: Encuentro, 2009.

Husserl, E., Meditaciones cartesianas, México: FCE, 1994.

Löwith, K., Heidegger, pensador de un tiempo indigente. Sobre la posición de la filosofía en el siglo XX, Buenos Aires: FCE, 2006.

Pöggeler, O., El camino del pensar de Martin Heidegger, Madrid: Alianza Editorial, 1993.

Rodríguez, R., La transformación hermenéutica de la fenomenología. Una interpretación de la obra temprana de Heidegger, Madrid: Tecnos, 1997.

Rodríguez, R., Heidegger y la crisis de la época moderna, Madrid: Sintesis, 2006.

Safranski, R., Un maestro de Alemania. Martin Heidegger y su tiempo, Barcelona: Tusquets, 1997.

Schürmann, R. y J. Caputo, Heidegger y la mística, Córdoba: Librería Paideia, 1995.

Volpi, F., Heidegger y Aristóteles, Buenos Aires: FCE, 2012.

Waldenfels, B., "Fenomenología de la experiencia en Edmund Husserl”, en: Areté, v. XXIX, 2 (2017), pp. 409-426. https://doi.org/10.18800/arete.201702.008 